\title{
The marketing countermeasure analysis of the off-season travel agency industry in Xinjiang
}

\author{
Zhu HuiDan, Ma Qiong *
}

Collage of Economics and Management Tarim university, Alar Xinjiang, 843300

\section{Key words: xinjiang;Travel agency;Off-season marketing}

\begin{abstract}
Xinjiang tourism industry started relatively late, development lags behind other provinces in China.The tourist season for June, July, August, September, eight months of off-season greatly influenced the operations of the travel agency industry in xinjiang.In this paper, from the objective factors and subjective factors and easy to analyze the reasons of the existence of xinjiang tourism industry season, on the basis of xinjiang travel off-season marketing strategy is put forward, in order to form the tourism industry in xinjiang "at the peak season of season take potential" good momentum of development.
\end{abstract}

\section{Introduction}

Xinjiang tourism industry started in the early $1980 \mathrm{~s}$, its development closely connected with China's reform, development and the development of the western region, and along with the development of economic globalization, gradually with international practice [1].Due to the rapid development of economy and startup of aid policy of xinjiang, the xinjiang travel agency quantity increasing, the scale is continually expanding.As shown in figure 1, 2007-2010 xinjiang increasing number of international travel agencies and domestic travel agencies, this shows that the travel agency industry in the steady development in xinjiang, the development space is also growing.Influenced by "July 5th incident" in 2009, 2010-2012, total travel agency in xinjiang is on the decline.2013 years later, with the passage of time, the adverse impact of the event to ease gradually, the number of domestic travel agencies slow rebound.

In recent years, in the implementation of xinjiang under the new situation, actively response to the call of the national development of the third industry in xinjiang, the development of the tourism industry has achieved the unprecedented achievement.As shown in table 1, 2000-2015 xinjiang tourism scale continues to expand, increasing income, reflect the travel agency industry in the steady development in xinjiang.

Table1 2000-2015 xinjiang and total income

\begin{tabular}{|c|c|c|c|c|c|}
\hline year & $\begin{array}{l}\text { The } \\
\text { receptio } \\
\mathrm{n} \\
\text { The } \\
\text { total } \\
\text { number } \\
\text { of(ten } \\
\text { thousan } \\
\text { d) }\end{array}$ & $\begin{array}{l}\text { The } \\
\text { entry } \\
\text { tourists } \\
\text { (ten } \\
\text { thousan } \\
\text { d) }\end{array}$ & $\begin{array}{l}\text { domesti } \\
\text { c } \\
\text { tourists } \\
\text { (ten } \\
\text { thousan } \\
\text { d) }\end{array}$ & $\begin{array}{l}\text { domestic } \\
\text { income } \\
\text { (one } \\
\text { hundred } \\
\text { million } \\
\text { yuan) }\end{array}$ & $\begin{array}{l}\text { The entry } \\
\text { income(doll } \\
\text { ars) }\end{array}$ \\
\hline
\end{tabular}




\begin{tabular}{cccccc}
\hline 2000 & 825.6 & 25.61 & 758 & 62.67 & 9494 \\
2001 & 827.3 & 27.3 & 839 & 71.8 & 9856 \\
2002 & 1028 & 27.54 & 968 & 83.95 & 9942 \\
2003 & 1017 & 17.05 & 1012 & 88.69 & 4858 \\
2004 & 1232 & 31.69 & 1242 & 108.96 & 9108 \\
2005 & 1533 & 33.11 & 1465 & 130.55 & 10009 \\
2006 & 1637.25 & 36.25 & 1661 & 149.14 & 12800 \\
2007 & 2169.84 & 43.84 & 2126 & 192.92 & 16190 \\
2008 & 2231.32 & 36.32 & 2195 & 197.95 & 13578 \\
2009 & 2133.50 & 35.50 & 2098 & 176.75 & 13663 \\
2010 & 3144.53 & 106.53 & 3038 & 281.13 & 36844 \\
2011 & 3961.5 & 132.5 & 3829 & 411 & 46579 \\
2012 & 4861 & 150 & 4711 & 542 & 55057 \\
2013 & 5205.59 & 156.73 & 5048.86 & 673.24 & 58500 \\
2014 & 4952.69 & 150.17 & 4802.52 & 619.53 & 49700 \\
2015 & 5726.33 & 168.36 & 5557.97 & 716.98 & 53384 \\
\hline
\end{tabular}

Most industry have market off-season and busy season, off-season income, market risk, some small and medium-sized enterprises even get failed but the off-season of winter [2].Travel agency industry is vulnerable to the influence of various factors, the season is very significant difference.In xinjiang in 2015 a month's reception of inbound tourists, the peak season of xinjiang is by the middle of October in mid-may, October off-season is coming in the middle of may;Off-season than the season of light, but there are still quite a number of hotels.Therefore, off-season potential performance to be reckoned with, off-season marketing has an important influence on the development of tourism industry.

\section{Travel agency industry off-season factors analysis in xinjiang}

A major cause of xinjiang tourism industry season difference: one is the xinjiang unique natural and humanistic environment, lag of traffic conditions, as well as traditional tourists travel habits of objective factors;Second, the travel agency industry's subjective factors, such as the off-season marketing consciousness, blind reduction countermeasures, off-season ignore tourism image and so on.

Natural and geographical conditions.One is xinjiang belongs to a typical temperate continental arid climate, winter cold and long, hot, dry summer, spring and autumn dry windy, suitable for travel time is not long.June to September visitors a year more, receive visitors accounted for $80 \%$ of the total, will be able to enter the scenic spot service facilities and transportation high tension;October in May of next year, influenced by climate, less tourists, facilities, a large number of idle.Second, xinjiang's tourism resources distribution is more dispersed, transportation network is relatively backward, and to some extent hindered the development of tourism industry in xinjiang.Such as xinjiang's most prestigious kanas scenic area, every winter and spring season snow mountain have to be out of business.

The influence of tourism of tourists.Group of climate conditions have important effects on tourist season, if the group climate in a certain period of time extremely hot or cold, local residents will travel to other destinations to heat or cold weather [3], such as xinjiang nalati prairie summer cool, in recent years has become a tourist summer resort in south China;If tourists humid climate, local residents will be curious about the desert tourism, as a new tourism industry, the taklamakan desert received widespread attention in recent years the tourism experience [4]. 
Traditional travel habits.Tourist leisure time is one of the important factors that affect the travel demand, and the national policy direct control of the tourists on holiday system of leisure time, the Spring Festival, May Day, National Day holiday is longer, the golden week "blowout" phenomenon in tourism, in the meantime create tourism revenues accounted for about half of the annual tourist income.And xinjiang in these three periods because of the influence of the natural and climate environment, tourism resource shortage, is in the off-season for, unable to grasp this golden opportunity, make the off-season more light.

The influence of the incident.According to maslow's hierarchy of needs theory, security is an important reference for measure whether the tourism environment comfortable.All nationalities in xinjiang's history, customs, different religious backgrounds, occasional conflict, after the incident, the travel agency industry will quickly turn into a trough.Such as "July 5th incident" broke out in 2009, to the number of xinjiang tourism basic is zero, the travel agency industry in xinjiang has experienced a year to recover after the "season", visible emergencies season influence greatly on the travel agency industry.

Travel agencies lack of efficient marketing solutions.Many travel agencies on the management of marketing performance evaluation and comprehensive quantitative analysis, makes the return on marketing level is low, so that the promotional budget cost more, but there is still no good tourism brand, tourists also does not have a significant increase in total, traveling light, the difference of the peak season is still a lot of [5].

Travel off-season propaganda consciousness.After part of xinjiang travel agency survey found that many of the small and medium-sized travel agencies into the tourist season, lose all promotional marketing consciousness, layoffs or even the whole travel a long vacation, which add to the off-season business dismal situation.

Ignore the tour image.Xinjiang tourism industry off-season marketing's main appeal is to fully reflect the real characteristics of tourism image, drawn out through effective marketing tool is transmitted to the target audience.In shaping their own characteristics in xinjiang in recent years, no serious analysis of the local natural and human environment, according to the market demand to scientific design attractive tourism image.

Off-season marketing existence violations.Individual travel agency in xinjiang in order to earn more profits in the offseason, using other brand or woo customers trashing other travel agency's reputation.These behavior severely disrupted the tourism market order and damaged the image of tourism industry, destroyed the country's legal system, the damage to the interests of both parties of supply and demand.Therefore, irregularities and become one of the factors that prompted off-season tourist form.

Price wars cause the perceptual off-season.Many travel agencies in xinjiang devotion to "low-cost low-quality", "high quality", ignore the possibility of development of "high quality" products.In the minds of many travel agency practitioners, for example, visitors will travel to xinjiang to xinjiang unique desert grassland landscape, so positioning of xinjiang tourism product promotion in the summer, the grass sprout out of the earth and pushed up the price of this period of time, but when visitors to reduce blind to slash prices, give a person with the arrival of the off-season psychological hint.But xinjiang folk performances, delicacies, ice and snow tourism projects such as equally attractive, if development tourist route of spring and winter, "high quality" project can also attract a significant number of tourists.This blind on behavior of the travel agency in xinjiang is to remind the arrival of the season, did not make good use of the unique humanities landscape resources in xinjiang.

Off-season destabilize staff layoffs.Some travel agency in xinjiang in the off-season layoffs, 
busy season to recruit a large number of employees, saves labor costs on the surface, actually makes travel agency operation state is not stable.One is the personnel fluidity big, employees sense of belonging is not strong, difficult to threw herself into her job;2 it is frequent turnover makes travel agency can't systematically industry experience.These factors will bring adverse effect to the travel agency, resulting in low light.

\section{Travel agency industry off-season marketing countermeasure analysis in xinjiang}

In the off-season tourist increase publicity, make originally not plan the tourist group to travel during this time period have hang out motivation.A is a powerful way to cheap for expanding the scope of the publicity, publicity scope enlargement increase travel agency profile, make the travel agency's recent price cut, value-added services such as promotion, quickly and efficiently.At the same time, advertising expense shoulds not be too big, can try to travel agencies joint advocacy, cost-sharing.Second, in view of the special group propaganda theme, such as in the ancient silk road and under the background of "region", to develop cultural tourism line, west culture and attract attention corps' red culture tourism.

Low price strategy can improve the competitiveness, attract customers in order to improve the sales performance of the travel agency.Is a long-term cooperation with the scenic area, hotel, with a low price tickets, discount suite project to win more passengers.Launch travel service group, the second is if a single passenger to travel at a lower price, will try to looking for companions to get low price group, caused the tourist group.

Make full use of the off-season tourist operation level of the employees understand the direction of tourism development at home and abroad, and enhance team cohesion.A new guide from skills of tour and political practice of tour timely matter to strengthen learning and accumulation, exercise more power of expression;Veteran of tour guide, can ask them to mastering many skills while specializing in, versatile, do have encyclopedic knowledge.

"At the peak season of season take potential", the so-called potential, is something of value for a long time, such as brand, reputation and strategic value, these are all factors that have a role to the tourism enterprise long-term market position [6].Xinjiang travel agencies to improve the participation degree of the brand and is the most simple and effective way is through a variety of marketing activities, increase the tourists experience of tourism products and brand experience, especially in the tourist unexpected situation, take the initiative to do all kinds of marketing activities, such as carrying out the test marketing activity in the off-season.Consumers tend to own in the offseason cost and price of the product is more sensitive, so this is what product best price and value acceptance test, test the tourists to acceptance of the product and price for the coming season to carry out the most suitable marketing activities.

New products often can cause the interest of consumer, will launch new products in off-season right in calm, making waves in the market, improve the popularity and attention, if you can make up for the off-season tourism market blank travel more new lines can bring unlimited business opportunities to the travel agency industry in xinjiang.Look from the natural environment, the same ice and snow in the winter with northeast of xinjiang tourism resources, such as Hal ice city has become one of the most popular winter tourism city in China, and xinjiang's tourism industry is still in the hibernate in winter.The xinjiang into new winter resort, can make the tourists to enjoy the western customs in xinjiang in the offseason, experience the unique western national sports and adventure of ice and snow sports.From the point of view of human environment, on the other hand, is known as exotic ethnic minority in xinjiang, high grade of tourism resources, natural landscapes and unique folk customs [7]., on the other hand, the xinjiang production and construction corps of 
the red tourism culture also distinctive, in the Chinese dream and the "way" of the background, developing red tourism market is able to provide new ideas for travel agency marketing [8].

Based on a variety of competent and objective reasons, there is a obvious season travel agency industry in xinjiang.In the face of frequent alternation of light, the peak season transformation, xinjiang tourism industry only with a positive attitude to overcome difficulties, to overcome the off-season marketing bottlenecks, improve sales performance.Low season is the best time to shape the tourism brand, as long as there is scientific and reasonable marketing strategy, can make the xinjiang tourism market bigger and stronger.Negative response is not the best to solve the problem, the travel agency industry in xinjiang should learn to reflect and adjust in the off-season.

\section{References:}

[1] Luo Yu. The problems existing in the tourism marketing and processing strategies [J]. Journal of economic and trade practice. 2015 (9).

[2] Derong Lin. Travel agency management [M]. Tsinghua university press. 2016.

[3] Wenhan. Lhasa tourism seasonal characteristic and control strategy research [J]. China business theory. 2015 (27) : 92-96.

[4] Xu Hui jie-ming Yang, Yang Qiao, Jinpeng Zhang. Travel agency marketing performance evaluation of the application and innovation in xinjiang, xinjiang comfort property of nature, for example [J]. Journal of resources development and the market. 2015, 31 (5) : 622-626.

[5] Lixia Ma, YuXiaoLing jie-ming Yang. Based on the SWOT quantitative method of the taklamakan desert tourism development strategy research [J]. Journal of enterprise economy. 2015 (2) : 148-151.

[6] Wang Jingchao yan-mei Chen. Advantages of developing tourism in national minority areas in China [J]. Foreign economic and trade. 2015 (3) : 103-104.

[7] Gan FengNing Mao Jinfeng. Out based on the seasonal tourist market marketing to explore - in Qingdao, for example [J]. Tourism through the "issue". 2015 (5).

[8] ya-ping wu, Shi Peixin zhi-yong Chen. The context of the Chinese dream red tourism destination marketing innovation [J]. Journal of guizhou and the social sciences. 2016 (1) : 128-135. 